Revista Brasileira de

Engenharia Agrícola e Ambiental

v. 16, n.5, p.521-528, 2012

Campina Grande, PB, UAEA/UFCG - http://www.agriambi.com.br

agriambi Protocolo 160.11 - 22/07/2011 • Aprovado em 23/02/2012

\title{
Biomassa e extração de nutrientes por plantas de cobertura ${ }^{1}$
}

\author{
Valéria S. Cavalcante ${ }^{2}$, Valdevan R. Santos ${ }^{3}$, Antônio L. dos Santos $\mathrm{N}$ eto $^{3}$, \\ Márcio A. L. dos Santos ${ }^{3}$, Cícero G. dos Santos $^{3} \&$ Leonardo C. Costa $^{3}$
}

\section{RESU MO}

Com o objetivo de avaliar a biomassa e a extração de nutrientes por plantas de cobertura no Agreste de Alagoas, implantou-se um experimento no campo experimental da Universidade Federal de Alagoas Campus Arapiraca. 0 delineamento experimental adotado foi em blocos casualizados, com oito tratamentos e quatro repetições. O s tratamentos foram: Crotalaria juncea, Crotalaria spectabilis, Cajanus cajan (L.) M illsp., Cajanus cajan, Canavalia ensiforme, D olichos lablab, M ucuna aterrima e a vegetação espontânea local (testemunha). A matéria verde foi avaliada em uma área de $1 \mathrm{~m}^{2}$ no florescimento de cada espécie sendo, em seguida, a biomassa secada em estufa a 65 으 até atingir massa constante para obter a matéria seca, em que foram extraídos os teores de macro e micronutrientes. As leguminosas apresentaram potencial para uso como adubo verde na região Agreste de Alagoas, além de teores de $\mathrm{N}$ superiores aos da vegetação espontânea não sendo diferentes entre si no acúmulo de $P, K, C a, M g, S, B$, $\mathrm{Mn}$ e Zn. A vegetação espontânea foi semelhante às leguminosas na produção de matéria seca. Dentre os tratamentos o Cajanus cajan arbóreo apresentou maior produção de matéria seca e acúmulo de $\mathrm{N}$ na parte aérea.

Palavras-chave: adubação verde, leguminosas, macronutrientes, micronutrientes

\section{Biomass production and nutrient removal by plant cover}

\begin{abstract}
A B STRACT
With the objective of evaluating the biomass production and nutrient removal by plant cover in the Agreste region of Alagoas, an experiment was conducted in the experimental field of the Federal U niversity of Alagoas - Campus Arapiraca. Randomized block design was used, with eight treatments and four replications. The treatments were: Crotalaria juncea, Crotalaria spectabilis, Cajanus cajan (L.) Mill sp., Cajanus cajan, Canavalia ensiformis, Dolichos lablab, Mucuna aterrima and the spontaneous local vegetation (control). The green matter in an area of $1 \mathrm{~m}^{2}$ during the flowering of each species was evaluated, and biomass was then dried in an oven at $65^{\circ} \mathrm{C}$ until constant weight for dry matter, in which the contents of macro and micronutrients were extracted. Leguminous plant showed potential for use as green manure in the Agreste region of Alagoas, with $\mathrm{N}$ contents higher than the spontaneous vegetation and not being different from one for the accumulation of $\mathrm{P}, \mathrm{K}, \mathrm{Ca}, \mathrm{Mg}, \mathrm{S}, \mathrm{B}, \mathrm{Mn}$ and $\mathrm{Zn}$. The spontaneous vegetation was similar to dry matter of legumes production. Among the treatments Cajanus cajan showed higher dry matter production and $\mathrm{N}$ accumulation in the aerial part.
\end{abstract}

Key words: green manure, leguminous, macronutrients, micronutrients

${ }^{1}$ Monografia da primeira autora apresentada ao curso de agronomia, UFAL.

2 Mestranda do Programa de Pós-graduação em Ciência do Solo da U niversidade Estadual Paulista "Júlio de Mesquita Filho" - Câmpus de Jaboticabal. Departamento de Solos e Adubos. Via de Acesso Paulo Donato Castellane, s/n. CEP 14884-900, Jaboticabal, SP. Fone: (16) 3209-2600. E-mail: valeriasantos_88@hotmail.com

${ }^{3}$ U FAL-Campus Arapiraca, Av. Manoel Severino Barbosa, s/n, Bom Sucesso, CEP 57309-005, Arapiraca, AL. Fone: (82) 3482-1831. E-mail: valdevan@yahoo.com.br; santosneto@gmail.com; mal.santo@pq.cnpq.br; cgomes_al@hotmail.com; leonardocorreia@hotmail.com 


\section{INTRODUÇÃO}

No município de Arapiraca, AL, destacava-se a cultura do fumo, que entrou em decadência nos anos 90, impondo aos agricultores a adesão de atividades que se adequassem às condições da região, dentre as quais o plantio de hortaliças. Atualmente se destaca o cultivo de alface (Lactuca sativa L.), de coentro (Coriandrum sativum L.) e de cebolinha-de-palha (Allium sp.).

Dados de Malavolta et al. (1997) indicam que, para se produzir 55.000 pés de alface são necessários $42 ; 10 ; 84 ; 17 ; 5$ e $2 \mathrm{~kg} \mathrm{ha}^{-1} \mathrm{de} \mathrm{N}, \mathrm{P}, \mathrm{K}, \mathrm{Ca}, \mathrm{Mg}$ e S, respectivamente; no entanto, as propriedades são de pequeno porte e os produtores não possuem recursos financeiros para suprir a demanda por insumos industriais.

Segundo a SEAGRI (2001), em Arapiraca, AL, os solos das áreas produtoras de hortaliças se caracterizam por apresentar $50 \%$ de baixos teores de $\mathrm{Ca}$ e $\mathrm{Mg} ; 60 \%$ com baix capacidade de troca catiônica (CTC); $27 \%$ com baixo nível de P; $36 \%$ com baixo de $\mathrm{Ke} 50 \%$ apresentam teores de médio a alto de $\mathrm{Al}$; com $73 \%$ dos solos ácidos. Com características químicas desfavoráveis, esses solos exigem grandes quantidades de fertilizantes orgânicos e minerais para suportar altas produtividades, o que encarece os custos de produção, visto que esses fertilizantes são derivados do petróleo e têm seus preços controlados pelo mercado internacional. Nesse contexto a adubação verde se torna alternativa para a sustentabilidade da agricultura na região, por se tratar de uma técnica que, por intermédio da cobertura vegetal do solo, proporciona melhorias em sua constituição química, física e biológica. Para esta finalidade pode-se utilizar tanto gramíneas como leguminosas, porém as últimas são mais usuais devido à sua capacidade de simbiose com bactérias do gênero Rizobium (Espíndola et al., 2004).

Além disso, as leguminosas proporcionam a ciclagem de nutrientes, extração e mobilização de macro e micronutrientes nas camadas mais profundas do solo e subsolo, maior CTC, maior teor de matéria orgânica, aumento no carbono da biomassa microbiana, baixo coeficiente metabólico, incremento no coeficiente microbiano, diminuição da densidade do solo e aumento na macroporosidade e na porosidade total (Osterroht, 2002; Faria et al., 2004; Carneiro et al., 2008; Andrade et al., 2009).

Ressalta-se que, na região Agreste de Alagoas, as leguminosas podem ser plantadas durante o inverno não havendo, desta forma, necessidade de investimento com irrigação. Outra vantagem da adubação verde é o controle das plantas daninhas, como verificado por Fernandes et al. (1999), que indicam o feijão-de-porco no controle de plantas invasoras, mesmo em menores densidades de semeadura; no entanto, para a determinação das espécies de leguminosas potencialmente produtoras de biomassa e recicladoras de nutrientes, é importante observar a interação entre as condições edafoclimáticas, genótipo e manejo.

Suzuki \& Alves (2006) obtiveram 46; 42; 42 e $32 \mathrm{t} \mathrm{ha}^{-1} \mathrm{de}$ matéria verde e $9 ; 8 ; 7$ e $6 \mathrm{t} \mathrm{ha}^{-1}$ de matéria seca de crotalária júncea, mucuna-preta, feijão-guandu e vegetação espontânea, respectivamente. Silva et al. (2002) verificaram, para a crotalária espectabilis, guandu anão, labe-labe e feijão-de-porco, produção de matéria verde de 12,$79 ; 28,97 ; 18,17$ e 30,24 t ha $^{-1} \mathrm{e}$ seca 2,$46 ; 6,84 ; 3,21$ e 6,05 t ha $^{-1}$, respectivamente.

Quanto ao teor de nutrientes, Ragozo et al. (2006) obtiveram, para o feijão-de-porco, guandu anão e labe-labe, teor de N, Ca, $\mathrm{B}, \mathrm{Cu}, \mathrm{Fe}$ e Zn superior aos teores no capim braquiária. Para a extração de nutrientes, Duarte Júnior \& Coelho (2008) observaram maior extração de N, P, Ca, Mg, S, Zn e Fe nas leguminosas, em comparação com a vegetação espontânea.

Apesar das vantagens de utilização da adubação verde, não há estudos para avaliar a eficiência das leguminosas na produção de biomassa e na reciclagem de nutrientes, na região Agreste de Alagoas. Nesse contexto, o trabalho foi realizado com o objetivo de avaliar a produção de biomassa e a extração de nutrientes por plantas de cobertura, na região Agreste de Alagoas.

\section{Matérial e MÉTODOS}

O trabalho foi desenvolvido no período de maio a setembro de 2009, na área experimental do Campus Arapiraca, Universidade Federal de Alagoas - município de Arapiraca, localizado nas coordenadas geográficas $9^{\circ} 45^{\prime} 58^{\prime \prime}$ de latitude sul e $35^{\circ} 38^{\prime} 58^{\prime \prime}$ de longitude oeste e altitude de $264 \mathrm{~m}$. Esta região é de transição entre a Zona da Mata e o Sertão Alagoano, cujo clima é classificado como do tipo 'As' tropical com estação seca de Verão, pelo critério de classificação de Köeppen. Os dados climatológicos estão apresentados na Figura 1.

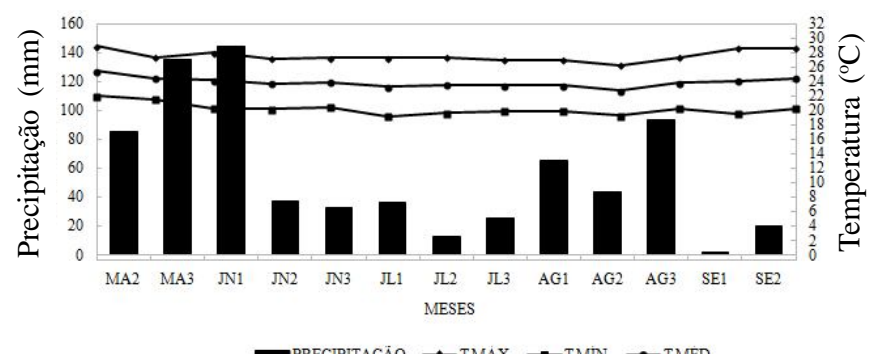

Fonte: INMET

Figura 1. Precipitação pluvial e temperatura média decendial do ar para o período de maio a setembro de 2009, no município de Arapiraca

A área experimental em que a pesquisa foi conduzida possui solo classificado como Argissolo Vermelho distrófico (EMBRAPA, 2006), cujas características químicas na profundidade de $0-20 \mathrm{~cm}$, foram apresentadas na Tabela 1.

O delineamento experimental adotado foi em blocos casualizados, com oito tratamentos com quatro repetições. Os tratamentos foram constituídos de sete espécies de leguminosas e da vegetação espontânea local (testemunha). As leguminosas utilizadas foram: crotalária juncea (Crotalaria juncea L.), crotalária espectabilis (Crotalária spectabilis), feijão guandu anão (Cajanus cajan (L.) Millsp), feijão guandu arbóreo (Cajanus cajan), labe-labe (Dolichos lablab), feijão-de-porco (Canavalia ensiformis) e mucuna-preta (Mucuna aterrima). 
Tabela 1. Resultado da análise química do solo realizada antes da instalação do experimento com adubos verdes no município de Arapiraca

\begin{tabular}{|c|c|c|c|c|c|c|c|c|c|c|c|c|c|}
\hline \multirow{2}{*}{$\underset{\left(\mathrm{H}_{2} \mathrm{O}\right)}{\mathrm{pH}}$} & \multirow{2}{*}{$\begin{array}{c}P \\
\left(\mathrm{mg} \mathrm{dm}^{-3}\right)\end{array}$} & \multirow{2}{*}{$\begin{array}{c}M .0 \\
\left(\mathrm{~g} \mathrm{dm}^{-3}\right)\end{array}$} & $K$ & $\mathrm{Ca}$ & $\mathrm{Mg}$ & Al & $\mathrm{H}+\mathrm{Al}$ & $T$ & \multirow{2}{*}{$\begin{array}{c}V \\
(\%)\end{array}$} & $\mathrm{Fe}$ & $\mathrm{Cu}$ & $\mathrm{Zn}$ & $\mathrm{Mn}$ \\
\hline & & & & & & $\mathrm{dm}^{-3}$ & & & & \multicolumn{4}{|c|}{$\left(\mathrm{mg} \mathrm{dm}^{-3}\right)$} \\
\hline 5,7 & 13 & 15 & 0,2 & 1,4 & 1,4 & 0,2 & 4,0 & 7,0 & 42,9 & 44,5 & 0,86 & 2,4 & 32 \\
\hline
\end{tabular}

Cada parcela experimental apresentou dimensões de 4 x $8 \mathrm{~m}$, totalizando $32 \mathrm{~m}^{2}$, com espaçamento entre linhas de $0,5 \mathrm{~m}$ e o espaçamento entre plantas foi o indicado pela empresa Piraí Sementes.

Para as avaliações, as plantas de cada parcela foram colhidas manualmente, rentes ao solo, em área útil de $1 \mathrm{~m}^{2} \mathrm{em}$ que a colheita ocorreu quando as plantas atingiram aproximadamente $50 \%$ do florescimento, para que todas as espécies fossem avaliadas no máximo desenvolvimento vegetativo caracterizando, então, o potencial produtivo de cada uma. O número de dias até a floração (DAF) está apresentado na Tabela 2 .

Tabela 2. N úmero de dias até o florescimento (DAF) de adubos verdes cultivados no município de Arapiraca

\begin{tabular}{lc}
\hline Tratamentos & № de dias até colheita do material vegetal \\
Vegetação espontânea & 104 \\
Crotalária júncea & 65 \\
Crotalária es pectabilis & 78 \\
Feijão guandu anão & 92 \\
Feijão guandu arbóreo & 129 \\
Labe-labe & 100 \\
Feijão-de-porco & 92 \\
Mucuna-preta & 100 \\
\hline
\end{tabular}

As amostras do material vegetal foram acondicionadas em sacos de nailon e levadas ao laboratório, onde foram obtidas as variáveis respostas: matéria fresca e matéria seca.

A matéria fresca foi determinada a partir da pesagem da biomassa verde proveniente do campo, utilizando-se de balança de precisão $0,01 \mathrm{~g}$; $\log$ o após, o material foi picado e colocado em saco de papel para secagem em estufa de circulação forçada de $\operatorname{ar}\left(65^{\circ} \mathrm{C}\right)$ até atingir massa constante com vista à determinação da matéria seca.

Com os resultados das matérias fresca e seca determinaramse os percentuais dessa relação, através da Eq. 1:

$$
\mathrm{R}_{\mathrm{S} / \mathrm{F}}(\%)=\frac{\mathrm{MS}}{\mathrm{MF}} \times 100
$$

em que:

$\mathrm{R}_{\mathrm{S} / \mathrm{F}}$ - percentual de matéria seca por matéria fresca, $\%$

MS - matéria seca, $g$

MF - matéria fresca, $g$

Após a determinação da matéria seca as amostras foram moídas em moinho tipo Wiley, acondicionadas em recipientes com 100 g e enviadas ao Laboratório de Nutrição Mineral de Plantas da Escola Superior de Agricultura Luiz de Queiroz para a determinação dos macronutrientes (N, P, K, Ca, Mg e S) e micronutrientes (B, Cu, Fe, Mn e Zn).
Os resultados das variáveis estudadas foram submetidos à análise de variância pelo teste $\mathrm{F}$ e as médias foram comparadas entre si pelo teste de Tukey ( $\mathrm{p}<0,05)$, utilizando-se o programa estatístico SISVAR ${ }^{\circledR}$ (Ferreira, 2003).

\section{RESULTADOS E DISCUSSÃO}

Os resultados de produção de matéria fresca, matéria seca (MS) e percentagem matérias seca e fresca $\left(\mathrm{R}_{\mathrm{S} / \mathrm{F}}\right)$ estão apresentados na Tabela 3. Observa-se que a vegetação espontânea apresentou maior produção de matéria fresca que a crotalária júncea, sendo similar às demais leguminosas. Este desempenho das plantas locais ocorreu por dois motivos: as espécies locais apresentaram maior adaptação às condições do ambiente, pois a área para a implantação do experimento estava em pousio; outro motivo foi o manejo das plantas nas parcelas, uma vez que as sementes de leguminosas foram semeadas nas linhas enquanto a vegetação espontânea se desenvolveu de forma natural, ocupando toda a área útil.

Tabela 3. Produção de matéria fresca ( $M F)$, matéria seca (MS) e percentagem matérias seca e fresca $\left(\mathrm{R}_{\mathrm{SF}}\right)$ de adubos verdes cultivados no município de Arapiraca

\begin{tabular}{llll}
\hline \multirow{2}{*}{ Tratamentos } & \multicolumn{1}{c}{ MF } & \multicolumn{1}{c}{ MS } & \multicolumn{1}{c}{$\mathbf{R}_{\mathbf{S / F}}$} \\
\cline { 2 - 3 } & \multicolumn{2}{c}{ (t ha- $^{-1} \mathbf{~}$} & (\%) \\
Vegetação espontânea & $35,5 \mathrm{a}$ & $7,2 \mathrm{ab}$ & $19,2 \mathrm{a}$ \\
Crotalária júncea & $13,5 \mathrm{~b}$ & $3,0 \mathrm{~b}$ & $23,2 \mathrm{a}$ \\
Crotalária es pectabilis & $19,0 \mathrm{ab}$ & $2,5 \mathrm{~b}$ & $16,7 \mathrm{a}$ \\
Feijão guandu anão & $16,5 \mathrm{ab}$ & $4,0 \mathrm{ab}$ & $26,0 \mathrm{a}$ \\
Feijão guandu arbóreo & $29,7 \mathrm{ab}$ & $8,7 \mathrm{a}$ & $29,5 \mathrm{a}$ \\
Labe-labe & $24,5 \mathrm{ab}$ & $3,2 \mathrm{~b}$ & $13,7 \mathrm{a}$ \\
Feijão-de-porco & $16,2 \mathrm{ab}$ & $3,0 \mathrm{~b}$ & $19,5 \mathrm{a}$ \\
Mucuna-preta & $30,0 \mathrm{ab}$ & $4,2 \mathrm{ab}$ & $14,5 \mathrm{a}$ \\
\hline CV (\%) & 35,9 & 44,5 & 15,4 \\
\hline
\end{tabular}

Médias seguidas de mesma letra na coluna não diferem entre si, pelo teste de Tukey $(P<0,05)$

Suzuki \& Alves (2006) observaram que a vegetação espontânea apresentou produção de matéria fresca semelhante à mucuna-preta e à crotalária júncea. Os resultados das leguminosas obtidos por esses autores foram superiores aos obtidos no presente estudo, devido a área estar em manejo há aproximadamente nove anos, com as culturas de milho, soja e algodão, enquanto neste trabalho a área estava em pousio. Também Heinrichs et al. (2005) constataram que a produção de matéria fresca da vegetação espontânea não apresentava diferença significativa com o guandu anão nem com a crotalária espectabilis. Teixeira et al. (2005) obtiveram produção de matéria verde de guandu anão de $2,5 \mathrm{t} \mathrm{ha}^{-1}$, valor inferior em comparação ao deste trabalho. Os autores verificaram, ainda, menor produção de matéria verde de feijão-de-porco com $13 \mathrm{t} \mathrm{ha}^{-1}$.

Quanto à produção de matéria seca o guandu arbóreo apresentou maior rendimento com $8,7 \mathrm{tha}^{-1}$ (Tabela 3 ), superior 
à crotalária juncea, crotalária espectabilis, labe-labe e feijãode-porco, assemelhando-se aos demais tratamentos. Esses resultados do guandu estão de acordo com os encontrados por Nascimento \& Silva (2004). No percentual de matéria seca na matéria fresca não houve diferença significativa (Tabela 3).

Pott et al. (2007) verificaram fitomassa seca semelhante à deste estudo para a crotalária júncea e guandu anão, indicando o guandu para solos de baixa fertilidade e pobres em fósforo. Santos et al. (2001) também indicam o guandu como espécie recuperadora de solos degradados em virtude da sua capacidade de promover aumento nos teores de carbono orgânico total e na CTC.

Salmi et al. (2006) notaram variação de 4,67 a 5,95 tha-1 para produção de matéria seca para seis espécies de guandu, resultado este inferior ao encontrado neste trabalho para o guandu arbóreo e semelhante para o guandu anão. Torres et al. (2008) obtiveram menor fitomassa seca no guandu anão e semelhante para crotalária júncea em comparação com este estudo.

Em razão da produção de matéria seca da vegetação espontânea ter sido superior às das crotalária júncea, crotalária espectabilis, labe-labe e feijão-de-porco, reforça-se que na vegetação local há plantas adaptadas às condições da área e com capacidade de produzir biomassa.

Segundo Carvalho et al. (2004), a maior germinação e o estabelecimento da vegetação espontânea local favorecem o aumento da produção de matéria seca. Em contrapartida, Favero et al. (2000) verificaram, estudando o crescimento e o acúmulo de nutrientes por plantas espontâneas e leguminosas no município de Sete Lagoas, MG, que o sistema com vegetação espontânea se mostrou menos eficiente que as leguminosas, quanto ao aporte de fitomassa seca. Ressalta-se que as condições locais favorecem uma espécie não apenas em comparação com as outras mas também entre as plantas de uma mesma espécie (Fernandes et al., 2007).

Carneiro et al. (2008) verificaram que a maior fitomassa de uma planta pode ser influenciada pela época de semeadura e, consequentemente, pelas condições do ambiente. Esses autores obtiveram, com a crotalária juncea, crotalária espectabilis, feijão-de-porco, guandu anão e labe-labe, cerca de três vezes mais biomassa seca que as plantas do presente estudo.

Neste contexto, para avaliar a eficiência de uma planta como adubação verde deve- se observar se ela produz grande quantidade de biomassa e se recicla elevada quantidade de nutrientes. A maior biomassa promove aumento na cobertura do solo e, em contrapartida, também maior teor de matéria orgânica, proporcionando benefícios como maior infiltração e armazenamento de água no solo, drenagem, aeração e interferência direta na resistência mecânica do solo (Suzuki \& Alves, 2006).

$\mathrm{Na}$ Tabela 4 se encontram os teores de macronutrientes nas leguminosas e na vegetação espontânea. Houve diferença significativa para os teores de macronutrientes nos diferentes adubos verdes.

O teor de N (Tabela 4) nas leguminosas foi superior ao da vegetação espontânea, resultado este semelhante aos obtidos por Ragozo et al. (2006); Silva et al. (2002); Duarte Júnior \& Coelho (2008); Favero et al. (2000); Silva et al. (2009); Cavigelli \& Thein (2003), o que comprova a importância das leguminosas em fixar $\mathrm{N}$ atmosférico por intermédio da quebra da tripla ligação de $\mathrm{N}_{2}$ pela simbiose com bactérias do gênero Rizobium. $\mathrm{O} \mathrm{N}$ fixado pelas plantas de cobertura ficará imobilizado no material vegetal e liberado gradativamente para a cultura em sucessão.

$\mathrm{Na}$ Tabela 4, a vegetação espontânea foi superior ao guandu arbóreo e mucuna-preta para o teor de P; ao guandu anão, guandu arbóreo e mucuna-preta em relação ao teor de $\mathrm{Mg}$ e à crotalária júncea, guandu anão, guandu arbóreo e mucunapreta para $\mathrm{Ca}$ e inferior apenas ao feijão-de-porco para o S. Esses resultados discordam dos encontrados por Duarte Júnior \& Coelho (2008), que obtiveram teor de macronutrientes para vegetação espontânea inferior em comparação com as leguminosas, sendo o K o único nutriente que apresentou maior teor na vegetação espontânea. Cavigelli \& Thein (2003) verificaram maior teor de fósforo e nitrogênio nas leguminosas em relação às plantas forrageiras.

Segundo Favero et al. (2000), em termos de nutrientes a vegetação espontânea apresentou maior teor de $\mathrm{K}, \mathrm{Mg}$ e P; no entanto, em relação ao $\mathrm{Ca}$ e $\mathrm{N}$, as leguminosas apresentaram teor superior à vegetação espontânea, porém algumas plantas locais apresentaram teor de Ca similar às leguminosas. Esses resultados são semelhantes aos do presente trabalho.

Verifica-se, na Tabela 4, que o teor de $\mathrm{K}$ na crotalária espectabilis foi superior ao da crotalária júncea, guandu anão, guandu arbóreo e mucuna-preta, apesar de esta espécie ter apresentado baixa quantidade de matéria seca em relação às demais leguminosas (Tabela 3). Silva et al. (2002) também relataram maior teor K na crotalária espectabilis, com a produção

Tabela 4. Teores de macronutrientes na matéria seca da parte aérea de adubos verdes cultivados no município de Arapiraca

\begin{tabular}{|c|c|c|c|c|c|c|}
\hline \multirow{2}{*}{ Tratamentos } & $\mathbf{N}$ & $\mathbf{P}$ & $K$ & $\mathrm{Ca}$ & $\mathrm{Mg}$ & $\mathbf{S}$ \\
\hline & \multicolumn{6}{|c|}{$\left.\left(g^{k g}\right)^{-1}\right)$} \\
\hline Vegetação espontânea & $13,0 \mathrm{~b}$ & $4,0 \mathrm{a}$ & $19,5 a b c$ & $11,5 \mathrm{a}$ & $3,7 \mathrm{a}$ & $1,0 \mathrm{~b}$ \\
\hline Crotalária júncea & $22,0 \mathrm{a}$ & $3,0 a b$ & 17,2 bc & $5,0 \mathrm{bc}$ & $3,0 a b c$ & $1,0 \mathrm{~b}$ \\
\hline Crotalária espectabilis & 28,0 a & $3,0 \mathrm{ab}$ & $27,5 a$ & $8,2 a b$ & $3,5 a b$ & $1,2 b$ \\
\hline Feijão guandu anão & $26,5 \mathrm{a}$ & $3,0 a b$ & $16,5 b c$ & $3,2 \mathrm{c}$ & $1,7 \mathrm{C}$ & $1,0 \mathrm{~b}$ \\
\hline Feijão guandu arbóreo & 24,2 a & $2,0 \mathrm{~b}$ & $13,7 \mathrm{c}$ & $3,2 \mathrm{C}$ & $2,2 \mathrm{bc}$ & $1,0 \mathrm{~b}$ \\
\hline Labe-labe & $30,2 \mathrm{a}$ & $3,0 a b$ & $22,2 a b$ & $11,5 \mathrm{a}$ & $3,5 a b$ & $1,5 a b$ \\
\hline Feijão-de-porco & $22,2 \mathrm{a}$ & $3,5 a b$ & $22,7 a b$ & $10,0 \mathrm{a}$ & $3,0 \mathrm{abc}$ & $2,0 \mathrm{a}$ \\
\hline Mucuna-preta & $24,5 \mathrm{a}$ & $2,2 b$ & $13,7 \mathrm{C}$ & $4,2 \mathrm{C}$ & $2,0 \mathrm{C}$ & $1,5 a b$ \\
\hline CV (\%) & 14,6 & 23,1 & 17,6 & 20,4 & 19,0 & 23,5 \\
\hline
\end{tabular}

Médias seguidas de mesma letra na coluna não diferem entre si, pelo teste de Tukey $(P<0,05)$ 
Tabela 5. Teores de micronutrientes na matéria seca da parte aérea de adubos verdes cultivados no município de Arapiraca

\begin{tabular}{lccccc}
\hline \multirow{2}{*}{ Tratamentos } & $\mathbf{B}$ & $\mathbf{C u}$ & $\mathbf{F e}$ & $\mathbf{M n}$ & $\mathbf{Z n}$ \\
\cline { 2 - 6 } & & & $\mathbf{( m g ~ k g}^{-\mathbf{1}}$ ) & & \\
Vegetação espontânea & $55,5 \mathrm{ab}$ & $7,5 \mathrm{~b}$ & $288,2 \mathrm{bc}$ & $99,5 \mathrm{a}$ & $31,0 \mathrm{ab}$ \\
Crotalária júncea & $35,5 \mathrm{c}$ & $8,0 \mathrm{~b}$ & $130,5 \mathrm{bc}$ & $65,0 \mathrm{a}$ & $21,2 \mathrm{bc}$ \\
Crotalária espectabilis & $58,7 \mathrm{a}$ & $14,2 \mathrm{a}$ & $264,0 \mathrm{bc}$ & $68,7 \mathrm{a}$ & $27,2 \mathrm{ab}$ \\
Feijão guandu anão & $37,7 \mathrm{c}$ & $11,0 \mathrm{ab}$ & $88,7 \mathrm{bc}$ & $70,5 \mathrm{a}$ & $25,2 \mathrm{bc}$ \\
Feijão guandu arbóreo & $38,7 \mathrm{c}$ & $8,5 \mathrm{~b}$ & $66,5 \mathrm{c}$ & $51,2 \mathrm{a}$ & $16,0 \mathrm{c}$ \\
Labe-labe & $44,7 \mathrm{bc}$ & $7,0 \mathrm{~b}$ & $114,2 \mathrm{bc}$ & $97,2 \mathrm{a}$ & $30,7 \mathrm{ab}$ \\
Feijão-de-porco & $55,5 \mathrm{ab}$ & $10,5 \mathrm{ab}$ & $353,2 \mathrm{ab}$ & $115,2 \mathrm{a}$ & $36,5 \mathrm{a}$ \\
Mucuna-preta & $48,0 \mathrm{abc}$ & $7,7 \mathrm{~b}$ & $593,0 \mathrm{a}$ & $123,0 \mathrm{a}$ & $29,2 \mathrm{ab}$ \\
\hline CV (\%) & 10,7 & 25,3 & 47,2 & 39,5 & 16,8 \\
\hline
\end{tabular}

Médias seguidas de mesma letra na coluna não diferem entre si, pelo teste de Tukey $(P<0,05)$

de matéria seca de $2,46 \mathrm{tha}^{-1}$, quantidade semelhante à deste trabalho.

Castro et al. (2005) não constataram diferença entre a vegetação espontânea e a crotalária júncea em relação ao teor de Mg, P e K. Silva et al. (2008) obtiveram, para a crotalária júncea, teores de $\mathrm{P}$ e $\mathrm{Ca}$ inferiores aos deste estudo e de $\mathrm{K}$ semelhante. Os autores destacam o teor de K, pois tal nutriente não faz parte de nenhum composto celular, razão pela qual sua liberaçãoé rápida.

Em contrapartida, Teixeira et al. (2005) verificaram que as leguminosas apresentam menor teor de potássio que outros adubos verdes. Além disso, eles observaram que, dentre as leguminosas, o guandu anão foi a espécie que apresentou menor teor de magnésio, corroborando com o presente trabalho.

Amabile et al. (1999) obtiveram, na primeira época de semeadura, na crotalária juncea, mucuna-preta e guandu, menores teores de N, P e K em comparação com o presente trabalho e concluíram que os teores de nutrientes variaram com a época de semeadura.

Quanto ao teor de micronutrientes (Tabela 5), não houve diferença significativa no teor de $\mathrm{Mn}$ entre os adubos verdes. A crotalária espectabilis apresentou maior teor de $\mathrm{B}$, não diferindo da vegetação espontânea, feijão-de-porco e mucunapreta.

A crotalária espectabilis destacou-se também por apresentar o maior teor de $\mathrm{Cu}$ (Tabela 5), sendo similar ao feijão-de-porco e guandu anão. Em relação ao teor de $\mathrm{Fe}$, a mucuna-preta foi semelhante ao feijão-de-porco e superior aos demais tratamentos. Da mesma forma, Silva et al. (2002) constataram maior teor de Fe na mucuna-preta.
O teor de Zn foi maior no feijão-de-porco que, por sua vez, só se diferenciou estatisticamente do guandu anão, guandu arbóreo e crotalária juncea (Tabela 5). Silva et al. (2008) observaram teores de micronutrientes semelhantes aos do presente estudo. Ressalta-se que a variação das espécies em relação ao teor de nutrientes sofre interferência da diferença na fertilidade do solo e assim a eficiência da reciclagem de nutrientes das plantas de cobertura depende da fertilidade préexistente.

Outro fator que influencia no desempenho das leguminosas é a época de incorporação, sendo a fase de florescimento o momento ideal para serem incorporadas ao solo; antecipação ou retardamento desse período é fator preponderante para atingir o objetivo esperado, pois as leguminosas sofrem interferência do fotoperíodo. Dias curtos diminuem a fase vegetativa, prejudicando o rendimento da planta (Jimenez et al., 2008; Suzuki et al., 2008).

A extração de N (Tabela 6) foi maior no guandu arbóreo em comparação com os outros tratamentos; isto se deve à sua maior produção de matéria seca (Tabela 3). Favero et al. (2000) também constataram que as plantas com maior produção de matéria seca apresentavam maior acúmulo de $\mathrm{N}$.

Os resultados da acumulação de $\mathrm{N}$ obtidos com o guandu arbóreo estão de acordo com os de Salmi et al. (2006), que verificaram variação de 188 a $261 \mathrm{~kg} \mathrm{ha}^{-1}$, e com os de Amado et al. (2001), que constataram acúmulo de $\mathrm{N}$, variando de 71 a 217 $\mathrm{kg} \mathrm{ha}^{-1} \mathrm{de} \mathrm{N}$ no consórcio entre leguminosas e milho porém se observou, para a extração de potássio, uma variação de 30 a 45 $\mathrm{kg} \mathrm{ha}^{-1}$, o que não concorda com este trabalho.

Tabela 6. Extração de macronutrientes na matéria seca da parte aérea de adubos verdes cultivados no município de Arapiraca

\begin{tabular}{lrrrrrr}
\hline \multicolumn{1}{c}{ Tratamentos } & $\mathbf{N}$ & $\mathbf{P}$ & $\mathbf{K}$ & $\mathbf{C a}$ & $\mathbf{M g}$ & $\mathbf{S}$ \\
\cline { 2 - 7 } & & \multicolumn{5}{c}{${\text { (kg ha }{ }^{-1} \text { ) }}$} \\
Vegetação espontânea & $91,0 \mathrm{~b}$ & $24,7 \mathrm{a}$ & $130,7 \mathrm{a}$ & $80,2 \mathrm{a}$ & $28,2 \mathrm{a}$ & $7,2 \mathrm{a}$ \\
Crotalária júncea & $65,0 \mathrm{~b}$ & $8,5 \mathrm{~b}$ & $53,0 \mathrm{a}$ & $15,7 \mathrm{~b}$ & $9,0 \mathrm{~b}$ & $2,7 \mathrm{a}$ \\
Crotalária espectabilis & $79,5 \mathrm{~b}$ & $8,5 \mathrm{~b}$ & $76,7 \mathrm{a}$ & $23,0 \mathrm{~b}$ & $9,5 \mathrm{ab}$ & $4,0 \mathrm{a}$ \\
Feijão guandu anão & $107,2 \mathrm{~b}$ & $18,2 \mathrm{ab}$ & $67,0 \mathrm{a}$ & $12,5 \mathrm{~b}$ & $7,0 \mathrm{~b}$ & $4,5 \mathrm{a}$ \\
Feijão guandu arbóreo & $218,5 \mathrm{a}$ & $10,7 \mathrm{ab}$ & $126,5 \mathrm{a}$ & $27,0 \mathrm{~b}$ & $18,5 \mathrm{ab}$ & $8,2 \mathrm{a}$ \\
Labe-labe & $101,5 \mathrm{~b}$ & $11,0 \mathrm{ab}$ & $75,0 \mathrm{a}$ & $38,2 \mathrm{ab}$ & $11,7 \mathrm{ab}$ & $5,0 \mathrm{a}$ \\
Feijão-de-porco & $71,0 \mathrm{~b}$ & $11,5 \mathrm{ab}$ & $72,5 \mathrm{a}$ & $31,7 \mathrm{ab}$ & $9,5 \mathrm{ab}$ & $6,2 \mathrm{a}$ \\
Mucuna-preta & $97,7 \mathrm{~b}$ & $10,2 \mathrm{ab}$ & $57,7 \mathrm{a}$ & $16,7 \mathrm{~b}$ & $8,0 \mathrm{~b}$ & $5,7 \mathrm{a}$ \\
\hline CV (\%) & 39,5 & 48,7 & 45,7 & 72,6 & 62,7 & 48,7 \\
\hline
\end{tabular}

Médias seguidas de mesma letra na coluna não diferem entre si, pelo teste de Tukey $(P<0,05)$ 
Tabela 7. Extração de micronutrientes na matéria seca da parte aérea de adubos verdes cultivados no município de Arapiraca

\begin{tabular}{|c|c|c|c|c|c|}
\hline \multirow{2}{*}{ Tratamentos } & B & $\mathrm{Cu}$ & $\mathrm{Fe}$ & $\mathrm{Mn}$ & $\mathbf{Z n}$ \\
\hline & \multicolumn{5}{|c|}{$\left(g_{\text {ha }}^{-1}\right)$} \\
\hline Vegetação espontânea & $381,0 \mathrm{a}$ & $50,2 a b$ & $2094,7 a b$ & 3443,0 a & 196,2 a \\
\hline Crotalária júncea & $119,0 \mathrm{~b}$ & $24,7 \mathrm{~b}$ & $403,2 \mathrm{ab}$ & 910,2 a & $67,5 \mathrm{~b}$ \\
\hline Crotalária espectabilis & $163,5 a b$ & $40,5 a b$ & $726,0 \mathrm{abc}$ & 1317,7 a & $75,2 \mathrm{~b}$ \\
\hline Feijão guandu anão & $152,7 \mathrm{ab}$ & $45,7 a b$ & $360,0 \mathrm{c}$ & $1127,2 a$ & $101,7 \mathrm{ab}$ \\
\hline Feijão guandu arbóreo & $350,5 a b$ & $74,5 \mathrm{a}$ & $606,0 a b c$ & $1538,2 \mathrm{a}$ & $143,2 a b$ \\
\hline Labe-labe & $151,7 \mathrm{ab}$ & $24,2 b$ & $386,2 \mathrm{c}$ & $2433,7 a$ & $102,7 \mathrm{ab}$ \\
\hline Feijão-de-porco & $177,7 a b$ & $24,5 b$ & $1133,5 a b c$ & 4094,7 a & $115,5 a b$ \\
\hline Mucuna-preta & $193,5 \mathrm{ab}$ & $40,7 a b$ & $2305,5 \mathrm{a}$ & 1900,2 a & $120,5 \mathrm{ab}$ \\
\hline CV (\%) & 51,9 & 46,1 & 71,8 & 67,8 & 41,2 \\
\hline
\end{tabular}

Médias seguidas de mesma letra na coluna não diferem entre si, pelo teste de Tukey $(P<0,05)$

Queiroz et al. (2007) obtiveram, estudando o comportamento de sete leguminosas perenes, maior produção de matéria seca e acúmulo de N, P e K, no guandu. O desempenho do guandu em extrair maior quantidade de fósforo é devido, sem dúvida, ao fato do seu sistema radicular ser mais profundo (Faria et al., 2004).

Entre as leguminosas a extração de $\mathrm{P}, \mathrm{K}, \mathrm{Ca}, \mathrm{Mg}, \mathrm{S}, \mathrm{Mn}, \mathrm{B}$ e $\mathrm{Zn}$ não apresentou diferença significativa (Tabelas 6 e 7). $\mathrm{O}$ mesmo não foi verificado por Heinrichs et al. (2005), que encontraram diferença entre o feijão-de-porco, a crotalária espectabilis e o guandu para a extração de $\mathrm{P}, \mathrm{K}, \mathrm{Ca}, \mathrm{Mg}$ e S destacando-se, dentre essas espécies, o feijão-de-porco.

Fernandes et al. (2007) constataram que as leguminosas acumularam maior quantidade de $\mathrm{Ca}$ e $\mathrm{Mg}$ com a utilização de calagem, indicando o suprimento mínimo de fósforo e da correção da acidez do solo para que as plantas reciclem o máximo de nutrientes. Referido manejo não foi realizado neste estudo haja vista que sua finalidade foi encontrar uma alternativa com baixo custo e aumentar a produção na região Agreste de Alagoas.

Extrações de K, S e Mn pelas leguminosas não diferiram da vegetação espontânea (Tabelas 6 e 7). O guandu arbóreo se destacou na extração de $\mathrm{Cu}$ (Tabela 7), assemelhando-se à vegetação espontânea, crotalária espectabilis, guandu anão e mucuna-preta, diferenciando-se da crotalária júncea, labe-labe e feijão-de-porco.

As plantas avaliadas para adubação verde apresentaram, dentre os micronutrientes, maior acúmulo de $\mathrm{Fe}$ e $\mathrm{Mn}$. Destacou-se a mucuna-preta em relação à quantidade de ferro, que foi superior ao guandu anão e ao labe-labe, e similar a vegetação espontânea, crotalária júncea, crotalária espectabilis, guandu arbóreo e feijão-de-porco (Tabela 7). $\mathrm{O}$ mesmo não foi observado por Silva et al. (2002), que verificaram menor acúmulo de Mn em relação ao presente trabalho.

Duarte Júnior \& Coelho (2008) observaram que as leguminosas crotalária juncea, feijão-de-porco e mucuna-preta extraíram maior quantidade de $\mathrm{P}, \mathrm{Ca}, \mathrm{Mg}, \mathrm{S}, \mathrm{Zn}$ e Fe que a vegetação espontânea. Esses resultados foram obtidos aos 92 dias após a semeadura, antes do florescimento de cada espécie vegetal. Deve-se observar que esses autores obtiveram resultados superiores ao deste estudo para estas leguminosas, como também para a extração de nutrientes, provavelmente por a área ser manejada com cana-de-açúcar antes da implantação do experimento.
Assim, o desempenho satisfatório das leguminosas na produção de biomassa e extração de nutrientes pode proporcionar benefícios ao solo. Segundo Silva et al. (2002), o acúmulo de $91,7 \mathrm{~kg} \mathrm{ha}^{-1}$ de N equivale a $204 \mathrm{~kg} \mathrm{ha}^{-1}$ de ureia ou $450 \mathrm{~kg} \mathrm{ha}^{-1}$ de sulfato de amônio.

Em relação à necessidade de $\mathrm{N}$ pelas principais hortaliças plantadas na região verifica-se, para a alface e o pimentão, que em solos de baixo teor de P e K, Ribeiro et al. (1999) indicam a exigência de $150 \mathrm{~kg} \mathrm{ha}^{-1} \mathrm{de} \mathrm{N}$, que corresponderia a $333 \mathrm{~kg} \mathrm{ha}^{-1}$ de ureia ou $750 \mathrm{~kg} \mathrm{ha}^{-1}$ de sulfato de amônio. Para a cebola, a quantidade de nitrogênio é de $120 \mathrm{~kg} \mathrm{ha}^{-1}$, o que equivale a 267 $\mathrm{kg} \mathrm{ha}^{-1}$ de ureia ou $600 \mathrm{~kg} \mathrm{ha}^{-1}$ de sulfato de amônio. Quando comparados esses valores com os da Tabela 6 , verifica-se que o guandu arbóreo acumulou mais $\mathrm{N}$ dentre os tratamentos, com 218,5 $\mathrm{kg} \mathrm{ha}^{-1}$, o que corresponde a $484 \mathrm{~kg} \mathrm{ha}^{-1}$ de ureia ou $1.093 \mathrm{~kg} \mathrm{ha}^{-1}$ de sulfato de amônio; portanto, supriria a necessidade de $\mathrm{N}$ de todas as hortaliças citadas; no entanto, deve-se observar que, em campo, as plantas avaliadas sofrem interferência dos fatores edafoclimáticos e do manejo.

\section{Conclusões}

1. As espécies de leguminosas avaliadas apresentaram potencial para uso como adubo verde na região Agreste de Alagoas.

2. A vegetação espontânea assemelhou-se às leguminosas em relação à produção de matéria seca.

3. O guandu arbóreo apresentou, dentre os tratamentos, maior produção de matéria seca e acúmulo de $\mathrm{N}$ na parte aérea.

4. As leguminosas apresentaram teores de $\mathrm{N}$ superiores aos da vegetação espontânea.

5. As sete leguminosas não apresentaram diferenças quanto à extração de $\mathrm{P}, \mathrm{K}, \mathrm{Ca}, \mathrm{Mg}, \mathrm{S}, \mathrm{B}, \mathrm{Mn} \mathrm{e} \mathrm{Zn}$.

\section{LITERATURA CITADA}

Amabile, R. F.; Fancelli, A. L.; Carvalho, A. M. Absorção de N, $\mathrm{P}$ e $\mathrm{K}$ por espécies de adubos verdes cultivadas em diferentes épocas e densidades num Latossolo vermelhoescuro argiloso sob cerrados. Revista Brasileira de Ciência do Solo, v.23, p.837-845, 1999. 
Amado, T. J. C.; Bayer, C.; Eltz, F. L. F.; Brum, A. C. R. Potencial de culturas de cobertura em acumular carbono e nitrogênio no solo no plantio direto e a melhoria da qualidade ambiental. Revista Brasileira de Ciência do Solo, v.25, p.189-197, 2001.

Andrade, R. S.; Stone, L. F.; Silveira, P. M. Cultura de cobertura e qualidade física de um Latossolo em plantio direto. Revista Brasileira Engenharia Agrícola e Ambiental, v.13, p.411-418, 2009.

Carneiro, M. A. C.; Cordeiro, M. A. S.; Assis, P. C. R.; Moraes, E. S.; Perreira, H. S.; Paulino, H. B.; Souza, E. D. Produção de fitomassa de diferentes espécies de cobertura e suas alterações na atividade microbiana de solo de cerrado. Bragantia, v.67, p.455-462, 2008.

Carvalho, M. A. C.; Athayde, M. L. F.; Soratto, R. P.; Alves, M. C.; Sá, M. E. Adubação verde e sistemas de manejo do solo na produtividade do algodoeiro. Pesquisa Agropecuária Brasileira, v.39, p.1205-1211, 2004.

Castro, C. M.; Almeida, D. L.; Ribeiro, R. L. D.; Carvalho, J. F. Plantio direto, adubação verde e suplementação com esterco de aves na produção orgânica de berinjela. Pesquisa Agropecuária Brasileira, v.40, p.495-502, 2005.

Cavigelli, M. A.; Thein, S. Phosphorus bioavailability following incorporation of green manure crops. Soil Science Society of America Journal, v.67, p.1186-1194, 2003.

Duarte Júnior, J. B.; Coelho, F. C. Adubos verdes e seus efeitos no rendimento da cana-de-açúcar em sistema de plantio direto. Bragantia, v.67, p.723-732, 2008.

EMBRAPA - Empresa Brasileira de Pesquisa Agropecuária. Centro Nacional de Pesquisa de Solos. Sistema brasileiro de classificação de solos. 2.ed. Brasília: Embrapa SPI, 2006. 306p.

Espíndola, J. A. A.; Almeida, D. L.; Guerra, J. G. M. Estratégias para utilização de leguminosas para adubação verde em unidades de produção agroecológica. Seropédica: Embrapa Agrobiologia, 2004. 24p. Documentos, 174

Faria, C. M. B.; Soares, J. M. M.; Leão, P. C. S. Adubação verde com leguminosas em videira no Submédio São Francisco. Revista Brasileira de Ciência do Solo, v.28, p.641-648, 2004.

Favero, C.; Jucksch, I.; Costa, L. M.; Alvarenga, R. C.; Neves, J. C. L. Crescimento e acúmulo de nutrientes por plantas espontâneas e por leguminosas utilizadas para adubação verde. Revista Brasileira de Ciência do Solo, v.24, p.171-177, 2000.

Fernandes, A. R.; Morais, F. I. O.; Linhares, L. C. F.; Silva, G. R. Produção de matéria seca e eficiência nutricional para $\mathrm{P}, \mathrm{Ca}$ e MG em leguminosas herbáceas. Acta Amazônica, v.37, p.169-176, 2007.

Fernandes, M. F.; Barreto, A. C.; Emídio Filho, J. Fitomassa de adubos verdes e controle de plantas daninhas em diferentes densidades populacionais de leguminosas. Pesquisa Agropecuária Brasileira, v.34, p.1593-1600, 1999.

Ferreira, D. F. Sisvar: Sistema de análise de variância versão 4.6. Lavras: UFLA/DEX, 2003.

Heinrichs, R.; Vitti, G. C.; Moreira, A.; Figueirêdo, P. A. M.; Fancelli, A. L.; Corazza, E. J. Características químicas de solo e rendimento de fitomassa de adubos verdes e de grãos de milho, decorrente do cultivo consorciado. Revista Brasileira de Ciência do Solo, v.29, p.71-79, 2005.
Jimenez, R. L.; Gonçalves, W. G.; Araújo Filho, J. V.; Assis, R. L.; Pires, F. R.; Silva, G. P. Crescimento de plantas de cobertura sob diferentes níveis de compactação em um Latossolo Vermelho. Revista Brasileira Engenharia Agrícola e Ambiental, v.12, p.116-121, 2008.

Malavolta, E.; Vitti, G. C.; Oliveira, S. A. Avaliação do estado nutricional de plantas: princípios e aplicações. 2.ed., Piracicaba: Potafos, 1997.319p.

Nascimento, J. T.; Silva, I. F. Avaliação quantitativa e qualitativa da fitomassa de leguminosas para o uso como cobertura de solo. Ciência Rural, v.34, p.947-949, 2004.

Osterroht, M. O que é uma adubação verde: Princípios e ações. Agroecologia Hoje, v.1, p.9-11, 2002.

Pott, C. A.; Müller, M. M. L.; Bertelli, P. B. Adubação verde como alternativa agroecológica para recuperação da fertilidade do solo. Ambiência, v.3, p.51-63, 2007.

Queiroz, L. R.; Coelho, F. C.; Barroso, D. G. Cultivo de milho no sistema de aléias com leguminosas perenes. Ciência e Agrotecnologia, v.31, p.1303-1309, 2007.

Ragozo, C. R. A.; Leonel, S.; Crocci, A. J. Adubação verde em pomar de cítrico. Revista Brasileira Fruticultura, v.28, p.6972, 2006.

Ribeiro, A. C.; Guimarães, P. A.; Alvarez, V. H. Recomendação para o uso de corretivos e fertilizantes em Minas Gerais $5^{\mathrm{a}}$ Aproximação. Viçosa: Comissão de Fertilidade do Solo do Estado de Minas Gerais, 1999. 7p.

Salmi, G. P.; Salmi, A. P.; Abboud, A. C. S. Dinâmica de decomposição e liberação de nutrientes de genótipos de guandu sob cultivoem aléias. Pesquisa Agropecuária Brasileira, v.41, p.673-678, 2006.

Santos, A. C.; Silva, I. F.; Lima, J. R. S.; Andrade, A. P.; Cavalcante, V. S. Gramíneas e leguminosas na recuperação de áreas degradadas: efeito nas características químicas de solo. Revista Brasileira de Ciência do Solo, v.25, p.10631071, 2001.

SEAGRI - Secretaria Municipal de Agricultura Estado de Alagoas. Prefeitura Municipal de Arapiraca. Levantamento de dados de análises de solo. Arapiraca: SEAGRI, 2001.

Silva, E. C.; Muraoka, T.; Buzetti, S.; Espinal, F. S. C.; Trivelin, P. C. O. Utilização do nitrogênio da palha de milho e de adubos verdes pela cultura do milho. Revista Brasileira de Ciência do Solo, v.32, p.2853-2861, 2008.

Silva, E. C.; Muraoka, T.; Villanueva, F. C. A.; Espinal, F. S. C. Aproveitamento de nitrogênio pelo milho, em razão da adubação verde, nitrogenada e fosfatada. Pesquisa Agropecuária Brasileira, v.44, p.118-127, 2009.

Silva, J. A. A.; Vitti, G. C.; Stuchi, E. S.; Sempionato, O. R. Reciclagem e incorporação de nutrientes ao solo pelo cultivo intercalar de adubos verdes em pomar de laranjeira-pêra. Revista Brasileira de Fruticultura, v.24, p.225-230, 2002.

Suzuki, L. E. A. S.; Alves, M. C. Fitomassa de plantas de cobertura em diferentes sucessões de culturas e sistemas de cultivo. Bragantia, v.65, p.121-127, 2006.

Suzuki, L. E. A. S.; Alves, M. C.; Suzuki, L. G. A. S.; Rodrigues, R. A. F. Fitomassa de plantas de cobertura sob diferentes sistemas de cultivo e sucessão de culturas em Selvíria - MS. Científica, v.36, p.123-129, 2008. 
Teixeira, C. M.; Carvalho, G J.; Furtine Neto, A. E.; Andrade, M. J. B.; Marques, E. L. S. Produçãode biomassa e teor de macronutrientes do milheto, feijão de porco e guandu anão em cultivo solteiro e consorciado. Ciência e Agrotecnologia, v.29, p.93-99, 2005.
Torres, J. L. R.; Pereira, M. G; Fabian, A. J. Produção de fitomassa por plantas de cobertura e mineralização de seus resíduos em plantio direto. Pesquisa Agropecuária Brasileira, v.43, p.421-428, 2008. 